\title{
Ictal cerebral perfusion related to EEG in drug resistant focal epilepsy of childhood
}

\author{
J H Cross, S G Boyd, I Gordon, A Harper, B G R Neville
}

\begin{abstract}
Objectives-To evaluate the EEG changes during seizures in children with drug resistant focal epilepsy who demonstrate hypoperfusion at the "seizure focus" interictally, but no perfusion change during the seizure.

Methods-Ictal EEG findings of six children with focal epilepsy who demonstrated hypoperfusion on rCBF SPECT after an interictal injection of ${ }^{9} \mathrm{Tc}^{\mathrm{m}}$ HMPAO concordant with the seizure focus, but who did not demonstrate rCBF change after an ictal injection (group 1) were reviewed. These were contrasted with the EEG data of six children matched as closely as possible for age, type of epilepsy, and pathology who did show hyperperfusion at the seizure focus on ictal scan when compared with the interictal study (group 2).

Results-The children in group 1 showed slowing of the EEG at the time of the ${ }^{99} \mathrm{Tc}^{\mathrm{m}}$ HMPAO injection relative to that seen at the onset of the seizure. Those in group 2 showed rhythmic activity, or sharp waves, or both on EEG at the time of injection. This last change was also seen consistently when the EEG data of a further 13 children who also showed ictal hyperperfusion at the seizure focus were reviewed.

Conclusion-Ictal rCBF does not invariably increase at the seizure focus in patients with drug resistant focal epilepsy.
\end{abstract}

Neurosciences Unit 1, Institute of Child

Health, The Wolfson

Centre, Mecklenburgh

Square, London

WC1N 2AP, UK

$\mathrm{J}$ H Cross

A Harper

B G R Neville

Department of

Radiology

I Gordon

Department of Clinical

Neurophysiology,

Great Ormond Street

Hospital for Children

NHS Trust, Great

Ormond Street,

London WC1N 3JH,

UK

Correspondence to:

Dr J H Cross.

Received 16 January 1996

and in final revised form

8 October 1996

Accepted 16 October 1996
$(\mathcal{F}$ Neurol Neurosurg Psychiatry 1997;62:377-384)

Keywords: electroencephalography; hypoperfusion; single photon emission computed tomography

Regional cerebral blood flow studies using ${ }^{99} \mathrm{Tc}^{\mathrm{m}}$ HMPAO single photon emission computed tomography (rCBF SPECT) have been advocated as a useful non-invasive preoperative tool in the presurgical evaluation of adults and children with drug resistant focal epilepsy. ${ }^{1-4}$ Scans after an ictal injection of ${ }^{99} \mathrm{Tc}^{\mathrm{m}}$ HMPAO have correctly identified the seizure focus in $93 \%-99 \%$ of cases by demonstrating a focal area of hyperperfusion. ${ }^{134}$ However, several factors influence reliable interpretation of ictal rCBF SPECT. The timing of the injection relative to seizure onset and offset is crucial, with a higher prediction rate noted after an ictal (when the injection is given during a seizure) as opposed to an immediate postictal injection (when the injection is given as soon after seizure offset as possible). ${ }^{56}$ There has also been some debate as to whether comparable results are obtained in temporal and extratemporal epilepsy. This may relate to the shorter duration of extratemporal seizures and the lower probabilty of obtaining an ictal injection. Injection after secondary generalisation has been shown to reliably identify the focus, particularly in the presence of persistant focal features during the clinical seizure or if injection is made soon after the generalisation. ${ }^{237}$ Finally, with the resolution of a single headed gamma camera, it may be assumed that minor perfusion changes within extensive underlying pathology may not be detected.

We report the EEG findings of a particular group of children with drug resistant focal epilepsy who underwent ictal and interictal rCBF SPECT as part of their investigation before consideration for surgery. These children showed hypoperfusion at the site of the clinical/EEG focus after interictal injection, but no change in perfusion pattern was noted after ictal injection.

\section{Methods}

PATIENTS

Of 50 children with drug resistant focal epilepsy who were investigated with interictal and ictal rCBF SPECT as part of their preoperative evaluation, 30 had technically satisfactory ictal EEG recordings for the seizure in which ${ }^{99} \mathrm{Tc}^{\mathrm{m}}$ HMPAO was injected. Of these, seizures could be localised in 25 children on the basis of clinical, EEG, and MRI data (23 have subsequently undergone surgery for the management of their epilepsy) and such localisation was termed the "seizure focus" Nineteen of these 25 children showed an area of hyperperfusion after the ictal injection of ${ }^{99} \mathrm{Tc}^{\mathrm{m}} \mathrm{HMPAO}$ concordant with the seizure focus. In 17 of these 19 this was concordant with an area of hypoperfusion after the interictal injection; in one there was no asymmetry of perfusion on interictal scan and in one hypoperfusion of an area non-concordant with the seizure focus. The remaining six children showed an area of hypoperfusion after interictal injection that was concordant with the seizure focus, but no perfusion change after ictal injection.

The six children who did not show a perfusion change formed group 1 for this study. They were then matched as closely as possible with regard to age, timing of ${ }^{99} \mathrm{Tc}^{\mathrm{m}} \mathrm{HMPAO}$ 
injection, temporal versus extratemporal epilepsy, and underlying pathology with a further group of six children (group 2) who did show a focal area of hyperperfusion after ictal injection concordant with the seizure focus. We then checked the findings from these two groups against those of the remaining 13 children (group 3).

\section{EEG TELEMETRY}

Time locked video/digital EEG recording was carried out at the bedside initially using a 16 channel Grass EEG machine linked to a videotape system developed in house ${ }^{8}$ (12 patients) and recently, a 32 channel cable system connected through an A/D card to a PC for display and storage of the signals (Stellate Systems Ltd) (13 patients). Remontaging was carried out off line. Videos were reviewed for seizure semiology and were also used to determine the exact timing of the injection of ${ }^{99} \mathrm{Tc}^{\mathrm{m}}$ HMPAO relative to the seizure onset. Changes on EEG at seizure onset, the time of ${ }^{99} \mathrm{Tc}^{\mathrm{m}} \mathrm{HMPAO}$ injection, and for the next 30 seconds were determined.

\section{SINGLE PHOTON EMISSION COMPUTED TOMOGRAPHY}

For the ictal rCBF SPECT children were admitted to the ward at least two days before the examination. Medication was withdrawn if seizure frequency was less than five a week. An intravenous cannula was inserted on the morning of the examination and continuous video-EEG monitoring was performed. A doctor trained in the technique remained in attendance throughout the test, and, when a typical seizure started, injected the ${ }^{99} \mathrm{Tc}^{\mathrm{m}} \mathrm{HMPAO}$ as soon after the seizure onset as possible. Children were scanned within three hours of injection and if necessary, sedated with intravenous midazolam $(0.5 \mathrm{mg} / \mathrm{kg})$ immediately before the scan.

For the interictal rCBF SPECT examination, the children were admitted to hospital and an intravenous cannula was inserted on the morning of the examination. The children were allowed to play and kept in a "normal" environment. All seizures were documented and the time of the last seizure noted. To minimise distress, the appropriate dose of ${ }^{99} \mathrm{Tc}^{\mathrm{m}}$ HMPAO was injected through the cannula while the children were on the ward. Sedation, when required, was achieved with intravenous midazolam given after the injection of ${ }^{99} \mathrm{Tc}^{\mathrm{m}}$ HMPAO at the time of the scan as with the ictal scan.

Images were acquired every $6^{\circ}$ for $360^{\circ}$ on a single headed Elscint SP6 gamma camera for a total acquisition time of 40 minutes. Images were subsequently reconstructed parallel to the temporal lobe and along the orbitomeatal line, to create two sets of axial slices as well as slices in the coronal and sagittal planes. The scans were reviewed visually for asymmetry of perfusion by two observers blind to all EEG or MRI data. Semiquantitative analysis was also performed, a difference of greater than $10 \%$ between matched regions in the two hemispheres being considered abnormal.

\section{Results}

GROUP 1

The mean age of the six children who did not show a perfusion change after ictal injection of ${ }^{99} \mathrm{Tc}^{\mathrm{m}} \mathrm{HMPAO}$ was 11 years 3 months (range 4 years 11 months to 16 years). Their mean age of onset of epilepsy was 2 years with a mean duration of epilepsy of 9 years (table 1). Three had temporal lobe epilepsy and three extratemporal epilepsy (two with hemisyndromes). The range of timing of injection of ${ }^{99} \mathrm{Tc}^{\mathrm{m}}$ HMPAO from the seizure onset was 24-85 seconds (mean 44 seconds), with a mean duration of seizure of 78 seconds. Five of the six were ictal injections (that is, during the seizure) and one was soon after clinical cessation (immediate postictal). The underlying pathology as determined by MRI was dysembryoplastic neuroepithelial tumour in two, porencephalic cyst in two, and hippocampal sclerosis in two (table 1; fig 1).

Table 2 shows the interictal and ictal EEG findings. The EEG changes were lateralised in five children in this group, and also localised in four. In four children there was slowing of activity relative to the onset of the seizure at the time of ${ }^{99} \mathrm{Tc}^{\mathrm{m}}$ HMPAO injection (fig 2B). Two children had slow activity at the onset of the seizure; in one (patient 5) there was attenuation followed by slow activity, with subsequent secondary generalisation at the time of the injection.

Table 1 MRI and SPECT data of group 1

\begin{tabular}{|c|c|c|c|c|c|c|c|}
\hline $\begin{array}{l}\text { Patient } \\
\text { No }\end{array}$ & $\begin{array}{l}\text { Age } \\
\text { (months) }\end{array}$ & $\begin{array}{l}\text { Age at first } \\
\text { seizure } \\
\text { (months) }\end{array}$ & $M R I$ & Interictal rCBF SPECT & $\begin{array}{l}\text { Duration of } \\
\text { seizure } \\
\text { recorded (s) }\end{array}$ & $\begin{array}{l}\text { Time of } \\
\text { injection of } \\
{ }^{9} \mathrm{Tc}^{m} \mathrm{HMPAO}(\mathrm{s})\end{array}$ & Ictal $r C B F$ SPECT \\
\hline 1 & 166 & 30 & R MCA infarct & $\begin{array}{l}\text { Absence activity } R \\
\text { parietal region }\end{array}$ & 40 & 35 & \multirow{6}{*}{$\begin{array}{l}\text { Absence activity } R \\
\text { parietal region } \\
\text { Decreased uptake } \\
\text { through whole } \\
\text { L hemisphere } \\
\text { Absence activity L } \\
\text { frontoparietal region } \\
\text { Hypoperfusion L } \\
\text { temporoparietal region } \\
\text { L temporoparietal } \\
\text { hypoperfusion } \\
\text { L temporal } \\
\text { hypoperfusion }\end{array}$} \\
\hline 2 & 59 & 18 & $\begin{array}{l}\text { Atrophy and gliosis } \\
\text { L hemisphere }\end{array}$ & $\begin{array}{l}\text { Decreased uptake } \\
\text { through whole } \\
\text { L hemisphere }\end{array}$ & 14 & 24 & \\
\hline 3 & 152 & 60 & L frontoparietal DNET & $\begin{array}{l}\text { Absence activity } \mathrm{L} \\
\text { frontoparietal region }\end{array}$ & 57 & 32 & \\
\hline 4 & 68 & 7 & $\begin{array}{l}\text { L temporal cortical } \\
\text { dysplasia }\end{array}$ & $\begin{array}{l}\text { Hypoperfusion } \mathrm{L} \\
\text { temporoparietal region }\end{array}$ & 80 & 36 & \\
\hline 5 & 155 & 6 & L hippocampal sclerosis & $\begin{array}{l}\text { L temporoparietal } \\
\text { hypoperfusion }\end{array}$ & $\begin{array}{l}98\left(2^{\circ} \text { gen }\right. \\
\text { at } 27 \mathrm{~s})\end{array}$ & 62 & \\
\hline 6 & 193 & 24 & L hippocampal sclerosis & $\begin{array}{l}\text { L temporal } \\
\text { hypoperfusion }\end{array}$ & 167 & 52 & \\
\hline
\end{tabular}

MCA = Middle cerebral artery; DNET = dysembryoplastic neuroepithelial tumour. 
Table 2 EEG data of group 1

\begin{tabular}{|c|c|c|c|c|}
\hline Patient No & Interictal EEG & EEG at seizure onset & $E E G$ at ${ }^{99} T c^{m}$ HMPAO injection & EEG over next 30 seconds \\
\hline 1 & $\begin{array}{l}\text { Occasional R centrotemporal } \\
\text { sharp wave, irregular 4-5/s }\end{array}$ & $\begin{array}{l}\text { Abrupt } 10-12 / \text { s rhythmic } \\
\text { activity } R\end{array}$ & $\begin{array}{l}\text { Attenuation, isolated sharp } \\
\text { wave, some slow }\end{array}$ & Gradually slow fades \\
\hline 2 & $\begin{array}{l}2 / \mathrm{s} \text { spikes/sharp waves } \mathrm{L} \\
\text { frontal region }\end{array}$ & $\begin{array}{l}\text { Attenuation followed by } \\
10-12 / \text { s rhythmic activity over } L\end{array}$ & Activity slows to $4-5 / \mathrm{s}$ & As at injection \\
\hline 3 & Irregular L temporal 4-5/s & $\begin{array}{l}\text { Abrupt } L \text { centrotemporal } \\
\text { slowing, } 1-1 \cdot 5 / \mathrm{s}\end{array}$ & $\begin{array}{l}\text { L sided } 2 / \mathrm{s} \text { at time of } \\
\text { injection }\end{array}$ & Slowly fades, but $2 / \mathrm{s}$ for next $30 \mathrm{~s}$ \\
\hline 4 & $\begin{array}{l}\text { Spike wave complexes } 2 / \mathrm{s} \\
\mathrm{L} \text { sided }\end{array}$ & $\begin{array}{l}\text { Spike wave } 7 / \mathrm{s} \text { before, then } \\
\text { bilateral attenuation, } L>R\end{array}$ & $\begin{array}{l}\text { Rhythmic } 3-4 / s \text { L posterior } \\
\text { temporal }\end{array}$ & $\begin{array}{l}\text { Rhythmic activity 3-4/s L } \\
\text { posterior temporal }\end{array}$ \\
\hline 5 & $\begin{array}{l}\text { Slow activity } 2-3 / \text {, spike wave } \\
\text { and spikes, often prominent } \\
\text { upper frontal, } R>L\end{array}$ & $\begin{array}{l}\text { Attenuation, then slow activity } \\
1-2 / \mathrm{s} \text { over both frontotemporal } \\
\text { regions }\end{array}$ & $2^{\circ}$ generalised, $4-5 / \mathrm{s}$ & Generalised, 4-5/s \\
\hline 6 & Slow activity $\mathrm{L}$ temporal & $\begin{array}{l}\text { L anterior temporal } 2-3 / \mathrm{s} \text {, } \\
\text { some sharp waves }\end{array}$ & Pronounced slowing $1 \cdot 5-2 / \mathrm{s}$ & Returns to $4 / \mathrm{s}$, later slows $<2 / \mathrm{s}$ \\
\hline
\end{tabular}

Figure 1 (A) Transverse MRI parallel to the axis of the temporal lobes of

patient 2 (group 1), reconstructed from a $3 D$ magnetisation prepared rapid acquisition gradient echo (MP-RAGE) data set $(T R=10 \mathrm{~ms}, T I=$ $200 \mathrm{~ms}, T E=4 \mathrm{~ms}$, flip angle $=12^{\circ}$ ). This shows atrophy and gliosis of $a$ large part of the left

hemisphere, particularly posteriorly. (B) Interictal and ictal ${ }^{99} \mathrm{Tc}^{m} \mathrm{HMPAO}$ SPECT; transverse sections parallel to the axis of the temporal lobes of patient 2. Decreased uptake through the left hemisphere is noted on both scans.

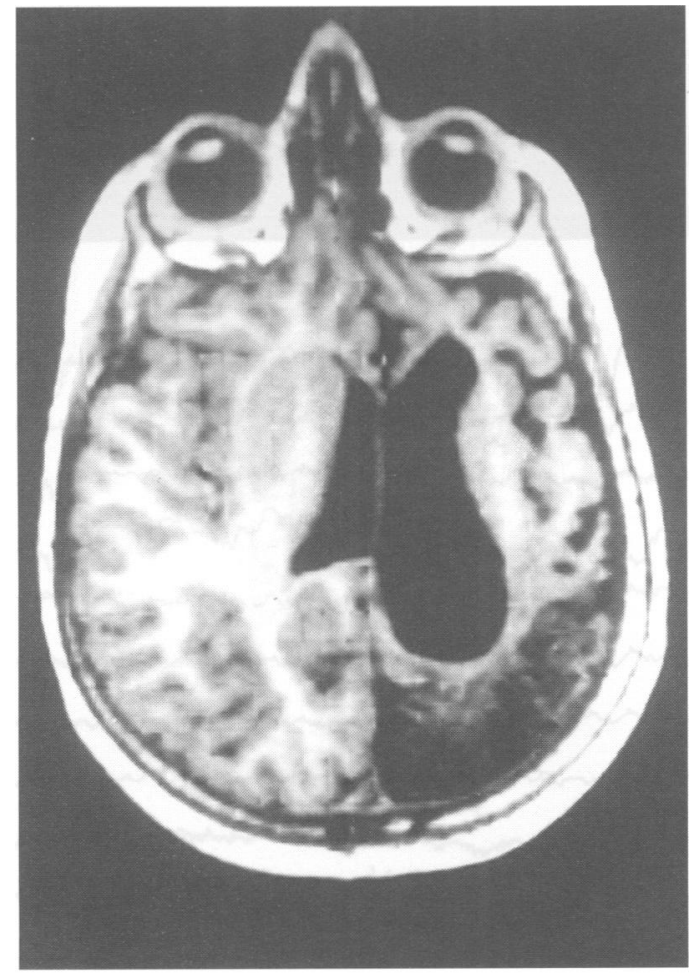

A

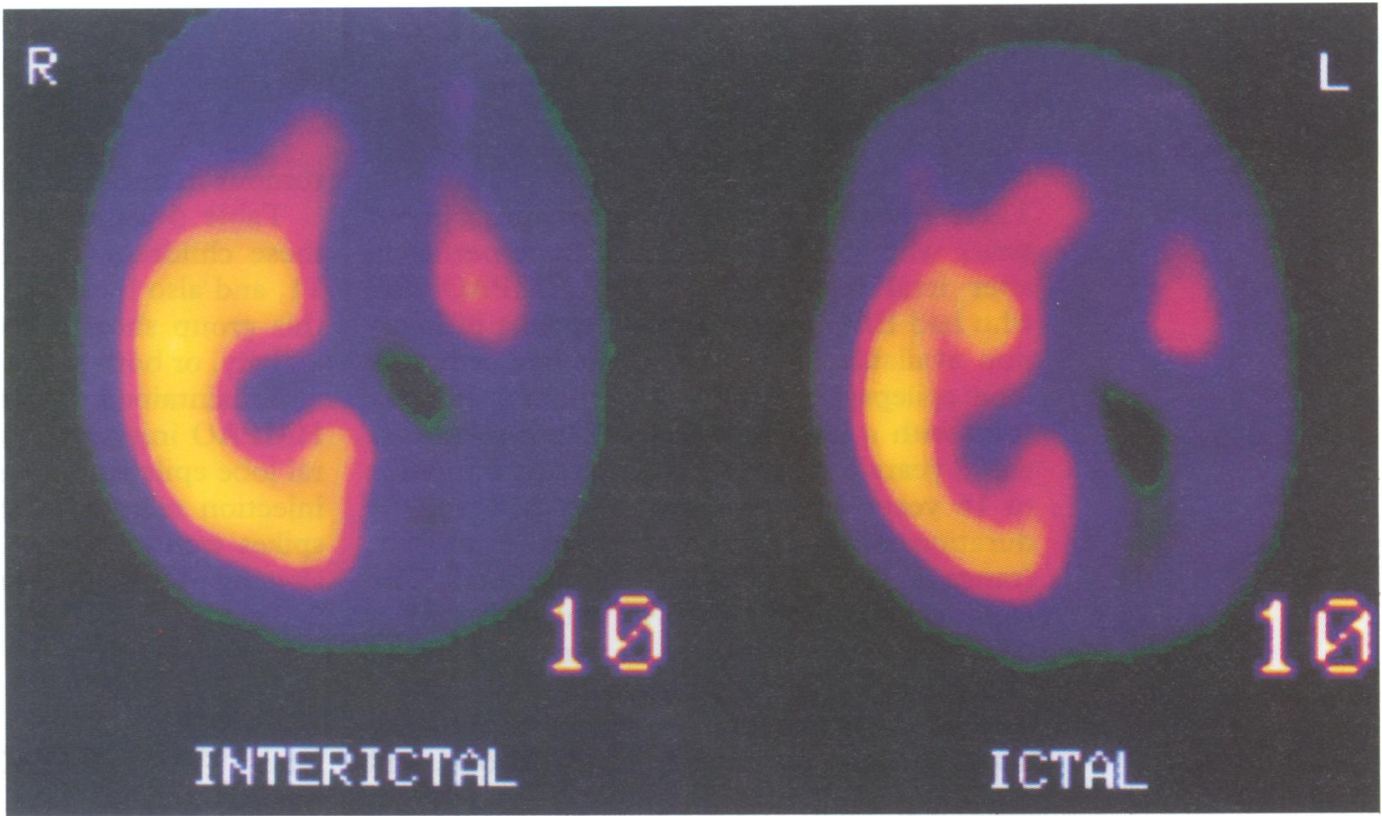

GROUP 2

The mean age of this group was 9 years 9 months (range 9 months to 12 years 5 months) with a mean age at onset of epilepsy of 2 years 5 months and mean duration of epilepsy 5 years 10 months (table 3; fig 3). Three had temporal lobe epilepsy and three extratemporal epilepsy (three with hemisyndromes). The range of timing of injection of ${ }^{99} \mathrm{Tc}^{\mathrm{m}}$ HMPAO from seizure onset was 39-78 (mean 54) seconds with five ictal and one immediately postictal injection. The mean duration of seizure recorded was 72 (range 56-103) seconds. The underlying pathology as determined by MRI was hippocampal sclerosis in two, porencephalic cyst in two, cortical dysplasia in one, and a dysembryoplastic neuroepithelial tumour in one (table 3; fig 3).

Table 4 shows the interictal and ictal EEG findings for this group. The EEG changes were lateralised in all children in this group and also localised in four. Five children had sharp waves, or rhythmic activity, or both of $>4 / \mathrm{s}$ at the onset of the seizure and this was seen in all children at the time of ${ }^{99} \mathrm{Tc}^{\mathrm{m}}$ HMPAO injection (fig 4B). In only one child (patient 9) was there marginal slowing of $6 / \mathrm{s}$ activity at seizure onset to $4 / \mathrm{s}$ at the the time of injection; this activity was rhythmic throughout. 
Figure 2 (A) Interictal and ictal ${ }^{99}{ }^{9} c^{m}$ HMPAO SPECT; coronal sections perpendicular to the axis of the temporal lobes of patient 3 (group 1). Both scans show an area of absence of activity in the left frontoparietal region (arrow). There was no area of hyperperfusion seen on the ictal scan. (B) $E E G$ at the time of injection of ${ }^{99} \mathrm{Tc}^{m} \mathrm{HMPAO}$ (arrowed) in patient 3. This shows irregular slow activity at $2 / s$.

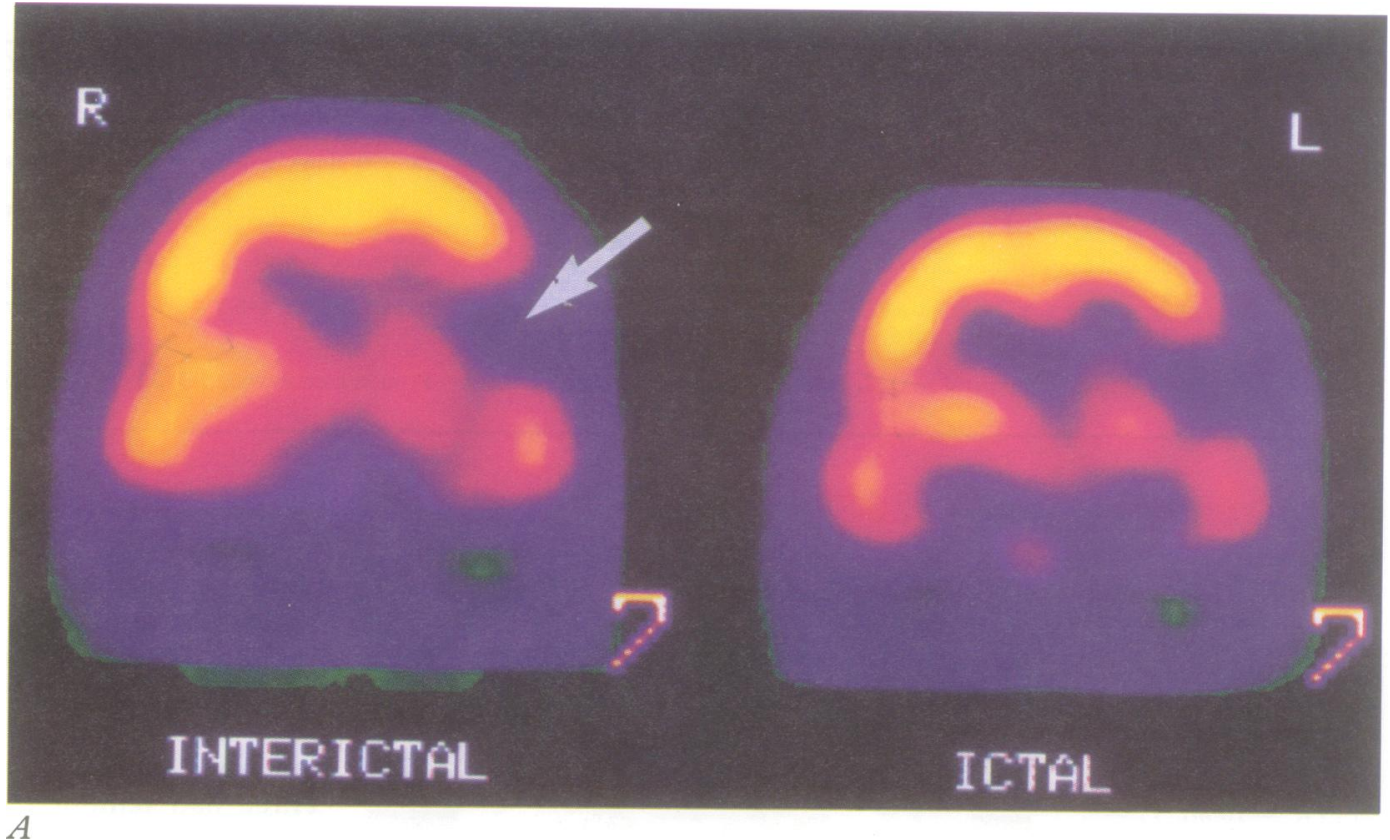

A
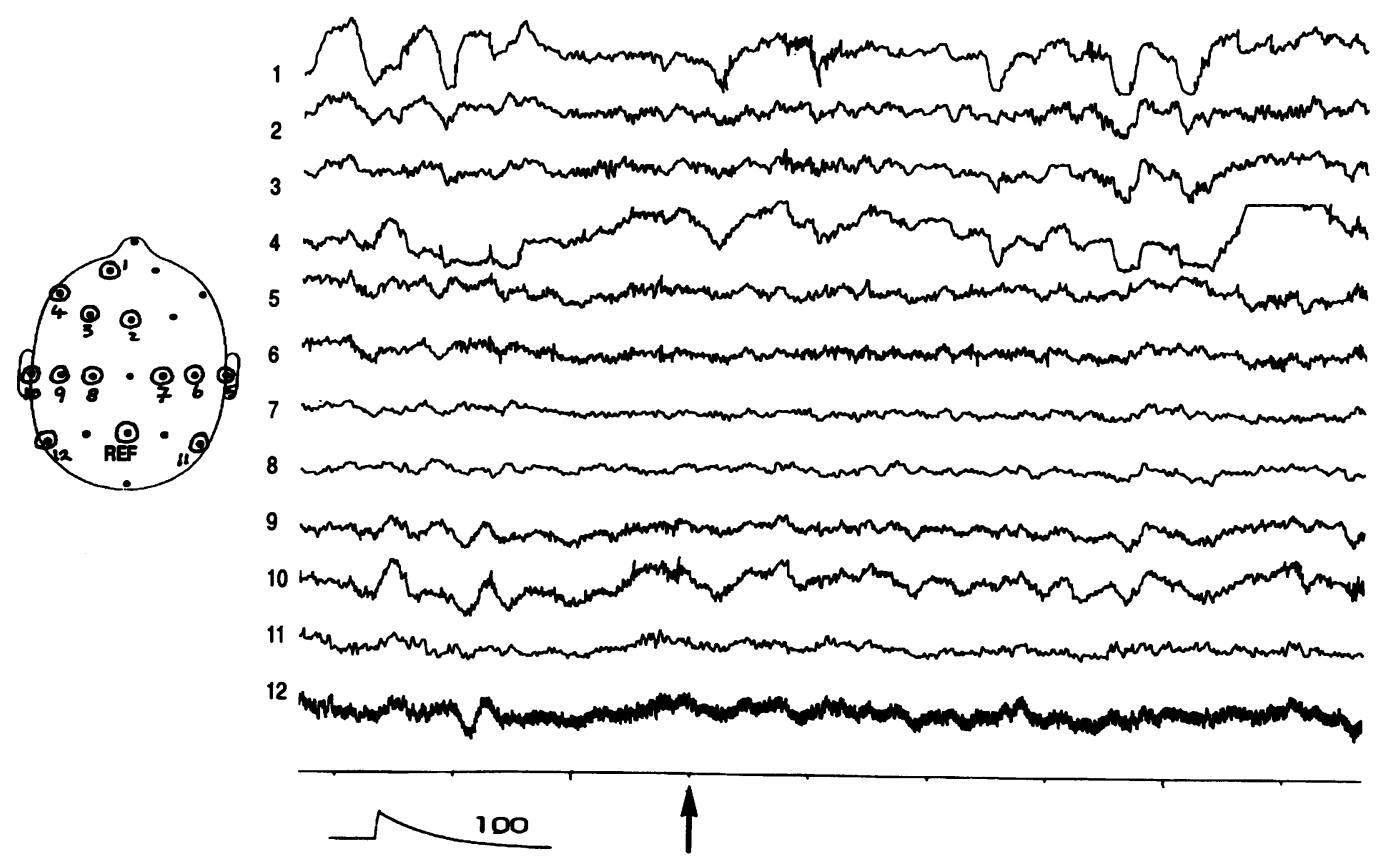

B

GROUP 3

These 13 children were those remaining in our series who showed an area of hyperperfusion after ictal injection of ${ }^{99} \mathrm{Tc}^{\mathrm{m}}$ HMPAO and who had EEG recordings at the time of injection available for review. Eight had temporal lobe epilepsy and five extratemporal epilepsy (two with a hemisyndrome). Their mean age was 8 years 6 months (range 2 years 6 months to 16 years 4 months) and they had a mean duration of epilepsy of 5 years 5 months (range 1 year to 13 years 10 months). The ictal scans comprised 10 in which the injections were ictal and three in which they were immediately postictal. The MRI in this group showed developmental anomalies in six (dysplasia in four, tuberous sclerosis in one, and dysembryoplastic neuroepithelial tumour in one), hippocampal sclerosis in three, hemiatrophy in one, hippocampal atrophy in one, tumour in one, and no abnormality in one.

Table 5 summarises the EEG data from these children. The EEG was lateralising in 11 , and also localising in eight. All children in this group showed sharp waves, or rhythmic activity, or both at the onset of the seizure that was maintained at least until the time of ${ }^{99} \mathrm{Tc}^{\mathrm{m}}$ HMPAO injection: two children with temporal lobe epilepsy showed slowing at the time of injection relative to the onset of the seizure; spikes were also seen in one and a degree of slowing of rhythmic activity in the other (4/s to $2-3 / s)$.

\section{Discussion}

Ictal ${ }^{99} \mathrm{Tc}^{\mathrm{m}}$ HMPAO SPECT has been reported to show focal hyperperfusion concordant with the seizure focus in around $95 \%$ of children with temporal and frontal lobe 
Table 3 MRI and SPECT data of group 2

\begin{tabular}{|c|c|c|c|c|c|c|c|}
\hline $\begin{array}{l}\text { Patient } \\
\text { No }\end{array}$ & $\begin{array}{l}\text { Age } \\
\text { (months) }\end{array}$ & $\begin{array}{l}\text { Age at first } \\
\text { seizure } \\
\text { (months) }\end{array}$ & $M R I$ & Interictal $r C B F$ SPECT & $\begin{array}{l}\text { Duration of } \\
\text { seizure } \\
\text { recorded (s) }\end{array}$ & $\begin{array}{l}\text { Time of } \\
\text { injection of } \\
{ }^{99} \mathrm{Tc}^{m} \mathrm{HMPAO}(\mathrm{s})\end{array}$ & Ictal $r C B F$ SPECT \\
\hline 7 & 110 & 30 & L MCA infarct & $\begin{array}{l}\text { Absence activity } L \\
\text { parietal region }\end{array}$ & $\begin{array}{l}72\left(2^{\circ} \text { gen }\right. \\
\text { at } 26 / \mathrm{s})\end{array}$ & 54 & \multirow{2}{*}{$\begin{array}{l}\text { As interictal with area } \\
\text { hyperperfusion } \\
\text { superior to defect } \\
\text { Hyperperfusion } L \\
\text { posterior parietal and } \\
\text { occipital }\end{array}$} \\
\hline 8 & 96 & 42 & $\begin{array}{l}\text { Encephalomalacia L } \\
\text { cerebral hemisphere } \\
\text { with atrophy L } \\
\text { brain stem }\end{array}$ & $\begin{array}{l}\text { Absence activity } L \\
\text { frontal/parietal, with } \\
\text { hypoperfusion temporal } \\
\text { and occipital lobes }\end{array}$ & 66 & 39 & \\
\hline 9 & 9 & $0 \cdot 3$ & $\begin{array}{l}\text { L posterior temporal } \\
\text { and inferior parietal } \\
\text { cortical dysplasia }\end{array}$ & $\begin{array}{l}\text { L temporoparietal - } \\
\text { occipital hypoperfusion }\end{array}$ & 82 & 41 & $\begin{array}{l}\text { L temporoparietal } \\
\text { hyperperfusion }\end{array}$ \\
\hline 10 & 149 & 84 & L temporal DNET & L temporal hypoperfusion & 78 & 78 & \multirow{3}{*}{$\begin{array}{l}\text { L temporal } \\
\text { hyperperfusion with } \\
\text { parietal hypoperfusion } \\
\text { L temporal } \\
\text { hyperperfusion } \\
\mathrm{L} \text { temporal } \\
\text { hyperperfusion }\end{array}$} \\
\hline 11 & 129 & 15 & $\begin{array}{l}\text { L hippocampal } \\
\text { sclerosis }\end{array}$ & Left parietal hypoperfusion & 56 & 69 & \\
\hline 12 & 101 & 3 & $\begin{array}{l}\text { L hippocampal } \\
\text { sclerosis }\end{array}$ & L temporal hyperperfusion & 81 & 42 & \\
\hline
\end{tabular}

MCA = Middle cerebral artery; DNET = dysembryoplastic neuroepithelial tumour.

Figure 3 (A) Transverse $M R I$ parallel to the axis of the temporal lobes of patient 8 (group 2) reconstructed from a $3 D$ $M P-R A G E$ data set. There is encephalomalacia of the left hemisphere. (B) Interictal and ictal ${ }^{99} \mathrm{TC}^{\mathrm{m}}$ HMPAO SPECT; transverse sections parallel to the axis of the temporal lobes of patient 8.

Although hypoperfusion of a large part of the left hemisphere is present on both scans, after an ictal injection an additional area of hyperperfusion is seen over the left parietooccipital region (arrowed).

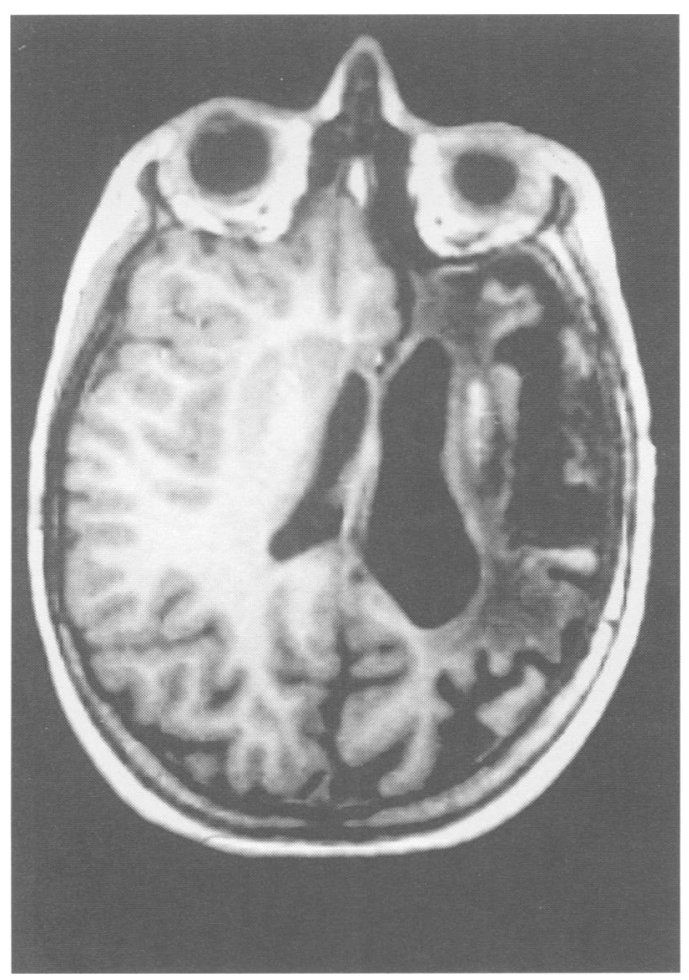

$A$ epilepsy. ${ }^{34}$ In this study we have reviewed children with intractable focal epilepsy who had an area of hypoperfusion on interictal $\mathrm{rCBF}$ SPECT which was concordant with the seizure focus (determined from clinical, EEG, and MRI data), but who did not show a change in rCBF after an ictal or immediate postictal injection. This seems to correlate with prominent slowing of the EEG at the time of the ${ }^{99} \mathrm{Tc}^{\mathrm{m}} \mathrm{HMPAO}$ injection. By contrast, when ictal focal hyperperfusion was demonstrated in groups 2 and 3, it was associated with rhythmic activity, sharp waves, or both at that time.

On review of the findings of group 1 , it became clear that none of the factors implicated in lack of ictal rCBF change, whether taken singly or in combination, could explain all the cases. The group included examples of definitely ictal as well as postictal injections, and of temporal as well as extratemporal epilepsy. Furthermore, whereas it might be considered that the resolution of the scan would not be sufficient to detect a change in rCBF within the extensive pathology in patient 2 (group 1 ; fig 1 ), changes were clearly shown in another child with comparable pathology (patient 8, fig 3).

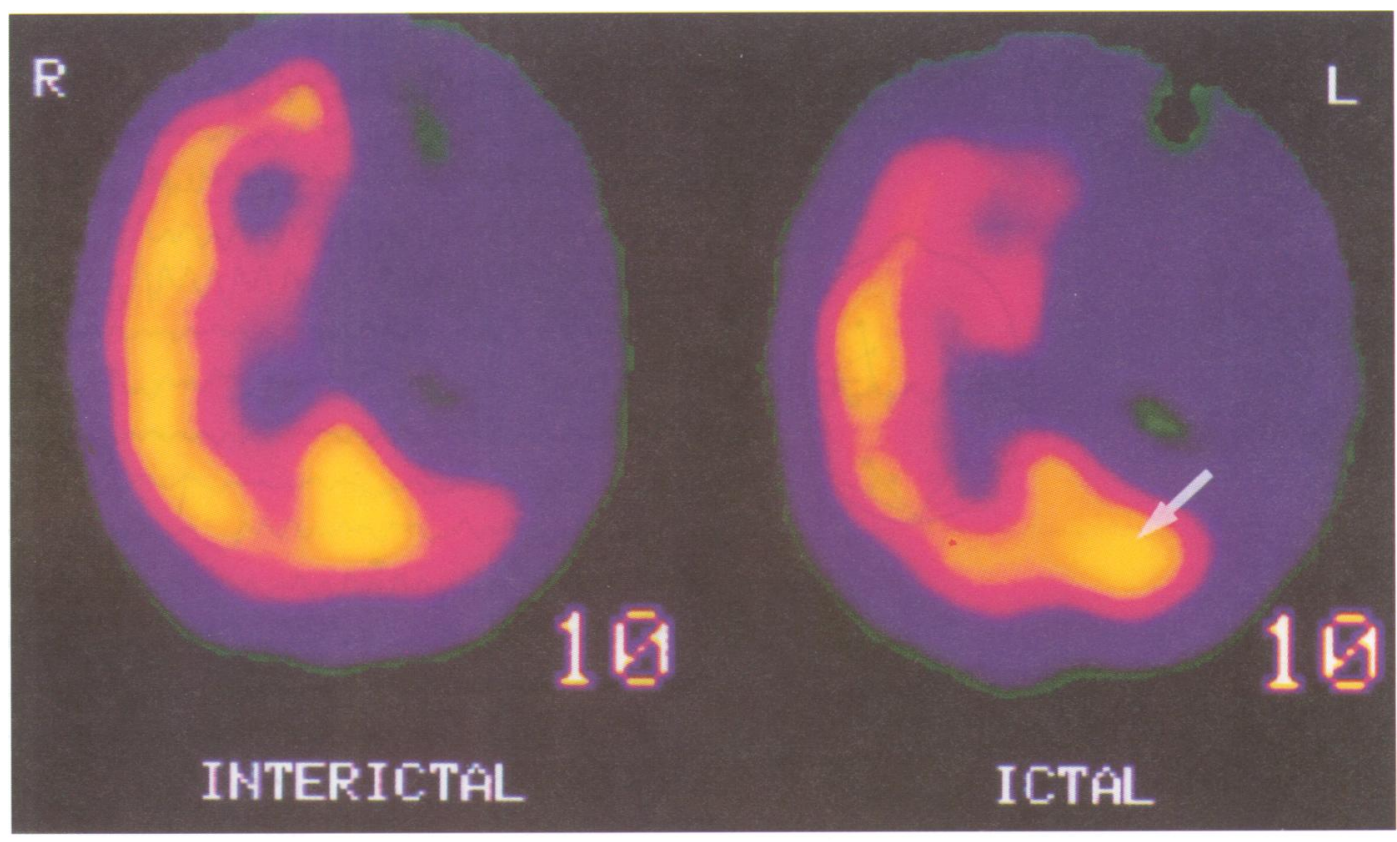


Table 4 EEG data of group 2

\begin{tabular}{|c|c|c|c|c|}
\hline Patient No & Interictal $E E G$ & EEG at seizure onset & $E E G$ at ${ }^{99} T c^{m} H M P A O$ injection & EEG over next 30 seconds \\
\hline 7 & $\begin{array}{l}2-3 / s \text { L temporal slow with } \\
\text { sharp waves }\end{array}$ & $\begin{array}{l}\text { Subtle increase in sharp, } \\
6-7 / \mathrm{s}\end{array}$ & $\begin{array}{l}\text { Increase in sharp waves on } L \\
\text { with rhythmic } 12-14 / \mathrm{s} \text { over } \\
R \text { occipitotemporal }\end{array}$ & $\begin{array}{l}\text { 2/s activity, multiple spikes over } \\
R \text {, later over } L\end{array}$ \\
\hline 8 & $\begin{array}{l}\text { Intermittent spikes/sharp } \\
\text { waves over L hemisphere }\end{array}$ & $\begin{array}{l}\text { Rhythmic fast } L \text { anterior } \\
\text { region, } 10-12 / \mathrm{s}\end{array}$ & Rhythmic sharp waves $4 / \mathrm{s}$ & Persists, particularly L temporal \\
\hline 9 & $\begin{array}{l}\text { Repetitive L temporo-occipital } \\
\text { sharp waves every } 2 \mathrm{~s}\end{array}$ & $\begin{array}{l}\text { L temporoparietal rhythmic } \\
\text { activity } 6 / \mathrm{s}\end{array}$ & L temporoparietal rhythmic $4 / \mathrm{s}$ & Persists as at injection \\
\hline 10 & L temporal sharp waves & $\begin{array}{l}\mathrm{L} \text { temporal rhythmic sharp } \\
\text { waves, } 3 / \mathrm{s} \text {, soon increases to } 6 / \mathrm{s}\end{array}$ & L temporal rhythmic sharp waves & $\begin{array}{l}\text { Stops abruptly } 4-5 / \mathrm{s} \text { after injection, } \\
\text { postictal L sided slow } 1-2 / \mathrm{s}\end{array}$ \\
\hline 11 & $\begin{array}{l}\text { Frequent epileptiform phenomena } \\
\text { bitemporally, L }>\mathbf{R}\end{array}$ & $\begin{array}{l}\text { Attenutation, followed by run } \\
2-3 / \mathrm{s} \mathrm{L} \text { anterior temporal }\end{array}$ & $\begin{array}{l}\mathrm{L} \text { anterior temporal } 6-7 / \mathrm{s} \text { sharp } \\
\text { wave activity }\end{array}$ & $\begin{array}{l}\mathrm{L} \text { anterior temporal sharp wave } \\
\text { activity } 4-5 / \mathrm{s} \text { continues }\end{array}$ \\
\hline 12 & $\begin{array}{l}\text { L mid temporal } 2-5 / s \text { sharp } \\
\text { waves and spikes }\end{array}$ & $\begin{array}{l}\text { 2/s sharp waves and runs } \\
4-5 / \mathrm{s} \text { rhythmic, } L\end{array}$ & $\begin{array}{l}\text { Runs of } L \text { temporal spikes with } \\
\text { rhythmic activity } 4-5 / s\end{array}$ & Continues as at injection \\
\hline
\end{tabular}

Figure 4 (A) Interictal and ictal ${ }^{99} \mathrm{Tc}^{\mathrm{m}}$ HMPAO SPECT; coronal sections perpendicular to the axis of the temporal lobes of patient 10 (group 2). The scan after an interictal injection shows left temporal hypoperfusion, whereas the scan after an ictal injection shows hyperperfusion of a similar area (arrowed). (B) EEG at the time of injection of ${ }^{99} \mathrm{Tc}^{m}$ HMPAO (arrowed) in patient 10. Rhythmic sharp waves at 6-7/s are seen over the left temporal region.

Acute slowing of scalp recorded EEG activities may be recognised as ictal, especially when this is rhythmic. ${ }^{9}$ This is usually interpreted, however, as evidence that the seizure

onset is relatively distant from the electrodes. Focal ischaemic changes may also produce localised slow activity, which is often irregular. Such irregular slow activity was found

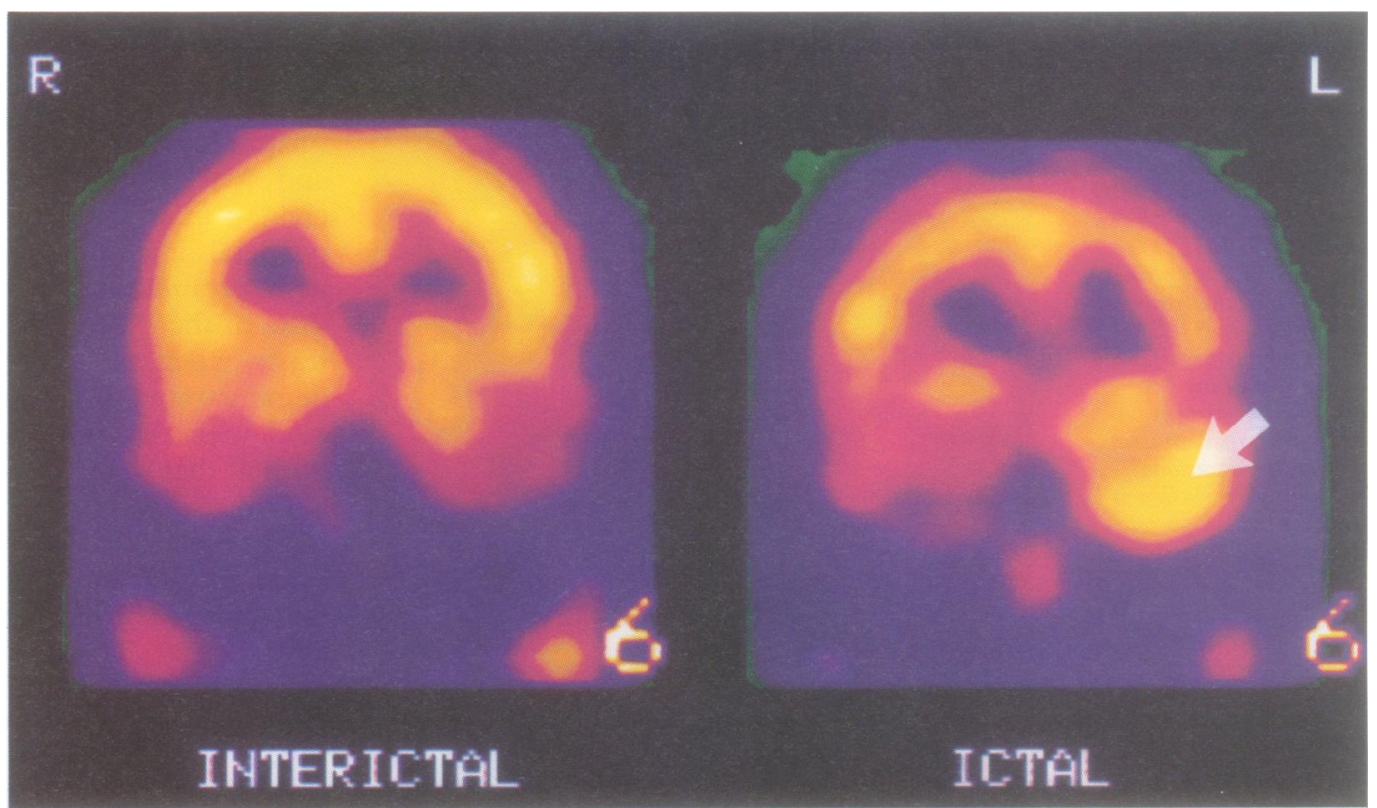

A

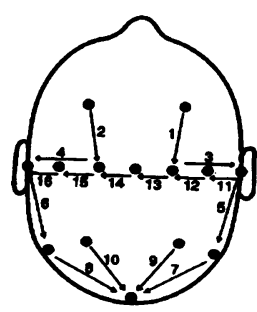

$$
\text { (n) }
$$


Table 5 Summary of EEG findings in group 3

\begin{tabular}{llll}
\hline EEG abnormality & $\begin{array}{l}\text { EEG at onset } \\
\text { of seizure }\end{array}$ & $\begin{array}{l}\text { EEG at time of } \\
\text { HMPAO } \text { injection }^{\mathrm{m}}\end{array}$ & $\begin{array}{l}\text { EEG over } \\
\text { next } 30 \mathrm{~s}\end{array}$ \\
\hline Sharp waves & 8 & 9 & 4 \\
Rhythmic activity & 5 & 4 & 4 \\
Attenuation & 0 & 0 & 0 \\
Slow activity $<4 / \mathrm{s}$ & 0 & 0 & 4 \\
Return to normal & 0 & 0 & 1 \\
\hline
\end{tabular}

consistently at the time of the injection of ${ }^{99} \mathrm{Tc}^{\mathrm{m}}$ HMPAO in those children in whom there was no change in an area of hypoperfusion between interictal and ictal scans; in four of the six this was a change relative to the onset of the seizure when more typical regional/focal rhythmic activity or sharp waves were seen. The notion that this area of hypoperfusion was concordant with the seizure focus was supported by the results of surgical resection.

Slowing of the EEG at the time of ${ }^{99} \mathrm{Tc}^{\mathrm{m}}$ HMPAO injection was a consistent finding in group 1 suggesting a real phenomenon, and implies that ischaemia rather than hyperaemia may be occurring during the seizure. Rowe et $a l^{5}$ correlated EEG findings (depth or sphenoidal) with postictal rCBF SPECT and found that the degree of postictal slow activity at the time of injection of ${ }^{99} \mathrm{Tc}^{\mathrm{m}} \mathrm{HMPAO}$ was significantly associated with the presence of lateral temporal hypoperfusion, consistent with our data. Hyperventilation tends to produce slowing of the EEG, and has been found in association with a reduction in $\mathrm{rCBF}$ as determined by Doppler ultrasound of the common carotid artery. ${ }^{10}$ Three of the children under study here had seizures triggered by hyperventilation; one from group 1 (patient 6) and two from group 3. In view of the demonstration in the two patients from group 3 of a clear area of temporal hyperperfusion concordant with the seizure focus, associated with rhythmic sharp waves at the onset of the seizure and at ${ }^{99} \mathrm{Tc}^{\mathrm{m}} \mathrm{HMPAO}$ injection, we think that it is unlikely that hyperventilation influenced the results in patient 6 .

Although the EEG findings in this study suggest that there may be relative ischaemia during focal seizures in some children rather than hyperperfusion, we were unable to determine whether there was further hypoperfusion on the ictal scan relative to the interictal scan as absolute quantitation of $\mathrm{rCBF}$ using ${ }^{99} \mathrm{Tc}^{\mathrm{m}}$ HMPAO SPECT is not currently possible in the clinical context. Penfield originally described "cortical anaemia" from arterial vasoconstriction during focal seizures induced by intraoperative stimulation. ${ }^{11}$ After further observations, Penfield suggested a sequence of events involving capillary dilatation during the seizure, and arterial vasoconstriction after the seizure, although recognising that the second could occur during the seizure. More recent studies with laser Doppler flowmetry during subdural monitoring of focal seizures in humans have also shown that a reduction in rCBF may occur. ${ }^{12}$ Although decreased rCBF may make tissue susceptible to further damage, the few children in this study preclude any comment on differences in clinical fea- tures between groups 1 and 2 such as seizure semiology and cognitive function.

Although there are many studies of $\mathrm{rCBF}$ during focal seizures, the underlying mechanisms responsible for the commonly reported increase during seizures remain poorly understood. This may be caused by increased metabolic demands, although the stimulus for, and control of, increased blood flow remains unclear. There are also few studies investigating cerebral metabolism during focal seizures. ${ }^{18}$ Fluorodeoxyglucose positron emission tomography $\left({ }^{18} \mathrm{FDG}\right.$ PET) studies are difficult to obtain ictally, but those reported describe both an increase ${ }^{13-16}$ and decrease ${ }^{13}$ in cerebral glucose metabolism at the seizure focus. Where this has been compared to $\mathrm{rCBF}$, a parallel increase in each has been shown, ${ }^{15} 16$ with no increase in oxygen consumption. ${ }^{15}$ Engel $e t$ al suggested that patterns seen on ictal ${ }^{18} \mathrm{FDG}$ PET in partial epilepsy are unique to each patient. ${ }^{13}$ Studies during generalised seizures in animals suggest an abolition of normal cerebral autoregulation ${ }^{17}$ and a local metabolic change, particularly ion exchange, may be responsible. ${ }^{18}$ If cerebral autoregulation is abolished, local factors in each individual may determine whether ictal rCBF is increased or decreased.

Our study has shown that ictal rCBF does not invariably increase at the seizure focus in patients with intractable focal epilepsy and that this correlates with irregular slowing on the EEG suggestive of ischaemia. This is of practical importance when interpreting ictal and interictal $\mathrm{rCBF}{ }^{99} \mathrm{Tc}^{\mathrm{m}}$ HMPAO SPECT studies and also emphasises the usefulness of concurrent EEG monitoring at the time of the ictal injection.

We thank the Wellcome Trust and Action Research for their support.

1 Berkovic SF, Newton MR, Chiron C, Dulac O. Single photon emission tomography. In: Engel J Jr, ed. Surgical treatment of the epilepsies. 2nd ed. New York: Raven Press, treatment of the

2 Cross JH, Gordon I, Jackson GD, et al. Children with intractable focal epilepsy: ictal and interictal $99 \mathrm{Tc}^{\mathrm{m}}$ HMPAO single photon emission computed tomography. Dev Med Child Neurol 1995;37:673-81.

3 Harvey AS, Bowe JM, Hopkins IJ, Shield LK, Cook DJ,

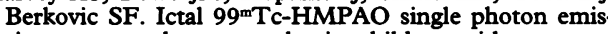
sion computed tomography in children with tempora lobe epilepsy. Epilepsia 1993;34:869-77.

4 Harvey AS, Hopkins IJ, Bowe JM, Cook DJ, Shield LK, Berkovic SF. Frontal lobe epilepsy: clinical seizure characteristics and localization with ictal 99m Tc-HMPAO SPECT. Neurology 1993;43:1966-80.

5 Rowe CC, Berkovic SF, Austin MC, McKay WJ, Bladin PF. Patterns of postictal cerebral blood flow in temporal lobe epilepsy: qualitative and quantitative analysis. Neurology 1991;41:1096-103.

6 Rowe CC, Berkovic SF, Austin MC, et al. Visual and quantitative analysis of interictal SPECT with technetium$99^{\mathrm{m}}$-HMPAO in temporal lobe epilepsy. $f$ Nucl Med 1991;32:1688-94.

7 Rowe CC, Berkovic SF, Sia ST, et al. Localization of epileptic foci with postictal single photon emission computed tomography. Ann Neurol 1989;26:660-8.

8 Lester M. Capturing the image with the signal: a system developed in a paediatric neurophysiology department which changes a routine EEG into a video/EEG. $f$ Electrophysiol Technol 1993;19:121-8.

9 Rivello JJ, Foley CM. The epileptiform significance of intermittent rhythmic delta activity in childhood. $f$ Child Neurol 1992;7:156-60.

10 Yamatani M, Konishi T, Murakami M, Okuda T. Hyperventilation activation on EEG recording in children with epilepsy. Pediatr Neurol 1995;13:42-5.

11 Penfield W. The evidence for a cerebral vascular mechanism in epilepsy. Ann Intern Med 1933;7:303-10.

12 Ronne-Engstrom E, Carlson H, Blom S, et al. Monitoring of cortical blood flow in human epileptic foci using laser cortical blood flow in human epileptic foci

13 Engel J, Jr., Kuhl DE, Phelps ME, Rausch R, Nuwer M 
Local cerebral metabolism during partial seizures. Neurology 1983;33:400-13.

14 Chugani HT, Rintahaka PJ, Shewmon DA. Ictal patterns of cerebral glucose utilization in children with epilepsy. Epilepsia 1994;35:813-22.

15 Franck G, Sadzot B, Salmon E, et al. Regional cerebral blood flow and metabolic rates in human focal epilepsy and status epilepticus. Adv Neurol 1986;44:935-48.

16 Kuhl DE, Engel J, Phelps ME, Selin C. Epileptic patterns of local cerebral metabolism and perfusion in humans determined by emission computed tomography of ${ }^{18} \mathrm{FDG}$ and ${ }^{13} \mathrm{NH}$. Ann Neurol 1980;8:348-60.

17 Plum F, Posner JB, Troy B. Cerebral metabolic and circulatory responses to induced convulsions in animals. Arch Neurol 1968;18:1-13.

18 Meyer JS, Gotoh F, Favale E. Cerebral metabolism during epileptic seizures in man. Electroencephalogr Clin Neurophysiol 1966;21:10-22.

\section{NEUROLOGICAL STAMP}

\section{Sigmund Freud (1856-1939)}

The Austrian neurologist and psychiatrist Sigmund Freud was born in Freiberg in eastern Moravia (now Pribor, Czechoslovakia) in 1856. As a student he already worked at the Institute of Physiology (University of Vienna) and had published papers on neurohistology. In 1885 Freud became Docent for Neuropathology and travelled to Paris for six months. There the introduction to the phenomena of hysteria and hypnotism brought a fundamental reorientation in Freud's scientific interests. Back in Vienna he withdrew from academic life and opened a practice. The cooperation with the physician Breuer-aimed at developing promising methods of treating hysteria-led to Freud's development of psychoanalysis as a therapeutic procedure, which at the same time provided him with the basis for his ideas on the instinctive structure of human behaviour, at the centre of which, in his opinion, was the sexual drive.

Sigmund Freud died in London on 23 September 1939. In 1938 the publications of this Jewish doctor had been "consigned to the flames". His teachingmuch criticised, rejected, misinterpreted, and in part disproved-had had a considerable and worldwide influence on the development not only of anthropology, psychology, psychiatry, and psychotherapy, but also on philosophy, art, and literature. Austria commemorated him in 1981 with a stamp.

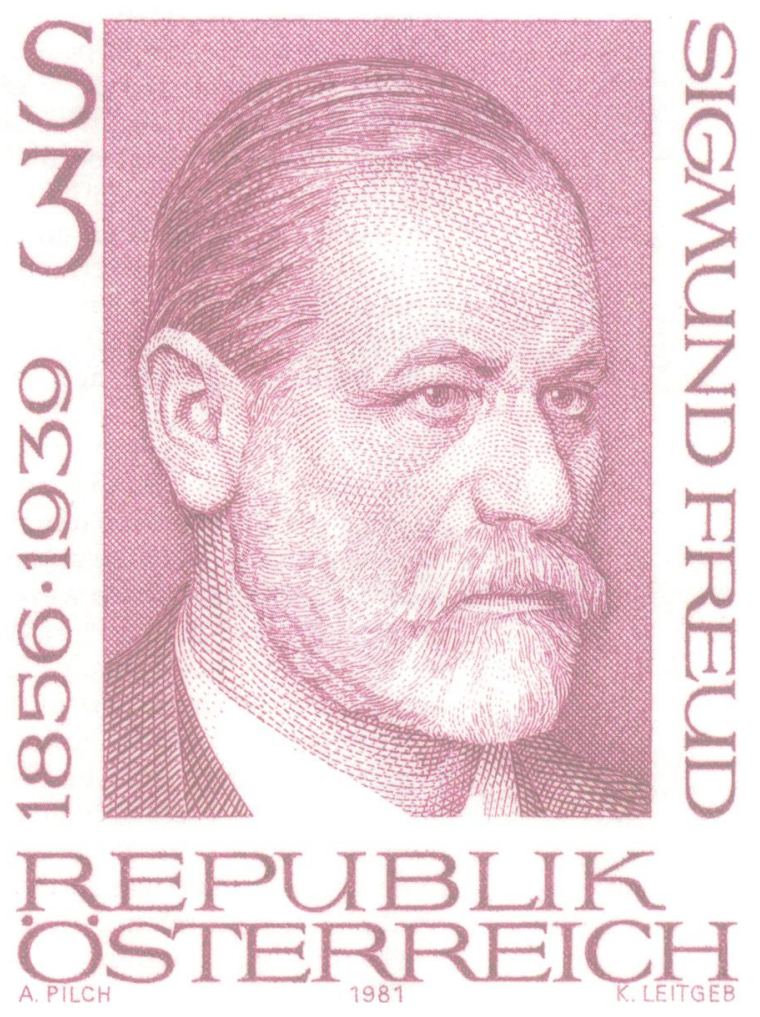

